\title{
Prevalence of Campylobacter spp. Isolated from Poultry, Human and Environment in Junagadh District of Gujarat, India
}

\author{
S. H. Sindhi ${ }^{1 *}$, B. S. Mathapati ${ }^{2}$, V. L. Parmar ${ }^{1}$, S. Marandi ${ }^{1}$, M. Sumankumar ${ }^{3}$, \\ B. B. Javia ${ }^{1}$, S. N.Ghodasara ${ }^{1}$, J. B. Kathiriya ${ }^{1}$, K. R. Bhedi ${ }^{1}$ and J. S. Patel ${ }^{4}$ \\ ${ }^{1}$ College of Veterinary Science and Animal Husbandry, Junagadh Agricultural University, \\ Junagadh, Gujarat, India \\ ${ }^{2}$ I.C.M.R.-National Institute of Virology, Sus Road, Pune, Maharashtra, India \\ ${ }^{3}$ Veterinary Public Health Division, ICAR-IVRI, Izatnagar, Bareilly, UP, India \\ ${ }^{4}$ Kamdhenu University, Gandhinagar, Gujarat, India \\ *Corresponding author
}

\section{A B S T R A C T}

\begin{tabular}{|c|}
\hline Keywords \\
\hline $\begin{array}{l}\text { Campylobacter, } \\
\text { Environment, } \\
\text { Human, Poultry }\end{array}$ \\
\hline Article Info \\
\hline $\begin{array}{l}\text { Accepted: } \\
24 \text { August } 2020 \\
\text { Available Online: } \\
10 \text { September } 2020\end{array}$ \\
\hline
\end{tabular}

A total of 500 samples, comprising 150 poultry meat, 150 intestinal (caeca), 50 water, 50 equipment swab and 50 workers' hand swabs from retail poultry meat outlets and 50 diarrhoeic stool samples from children under-5 years of age from children hospitals in Junagadh city were screened. The samples were subjected to isolation followed by confirmation using a multiplex PCR assay. Out of samples processed, highest isolation rate was observed in poultry intestinal contents $(38.67 \%$ each), followed by poultry meat (16\%), equipment swab (10\%), worker hand washing swab (6\%), human stools (4\%) and none of the isolate present in water samples. A total of 92 campylobacters $(18.4 \%)$ were isolated comprising 64 C. coli (12.8\%) and 28 C. jejuni (5.6\%). It may be concluded from the present study that Campylobacter spp. is highly prevalent in poultry, human and environment in Junagadh district of Gujarat region. The occurrence Campylobacter spp. in poultry intestinal contents, equipment swab and worker hands washing swab samples which indicate contamination of carcass may take place during slaughtering and/or post slaughtering processes. The findings on isolation of Campylobacter spp. from clinical cases of children further prove the importance of infection that necessitates the need for proper preventive measures to control the infection in food production and consumption.

\section{Introduction}

Campylobacter are microaerophilic Gramnegative bacteria causes gastroenteritis in humans and is responsible for 400-500 million cases of infection each year worldwide (Ruiz-Palacios, 2007). Campylobacter jejuni and C. coliare considered as potential agents responsible for several undiagnosed cases of diarrhea among children especially in developing countries including India (Silva et al., 2011; Ghorbanalizadgan et al., 2014). Incidence rate of $4.5 \%$ was observed in the southern India (Rajendran et al., 2012) and 10.28-13.5\% from diarrheic cases in North India (Ghosh et 
al., 2013).Campylobacter spp. have also been isolated from meat of different species, milk/milk products, vegetables, fruits, sewage, human stool and faecal samples of different animals (Kumar et al., 2001; Datta et al., 2003; Pallavi et al., 2015). These organisms are responsible for bacterial foodborne illness in European Union (Anonymous, 2005; Behringer et al., 2011), about 0.8 million cases in USA (Scallan et al., 2011) and 0.5 million cases in UK each year (Tam et al., 2011). The total number of cases reported to be caused by Campylobacter spp. was more than thrice the cases caused by Salmonella, Escherichia coli $\mathrm{O} 157: \mathrm{H} 7$ and Listeria monocytogenes altogether (CDC, 2008). Poultry act as the reservoir Campylobacter spp. and are the main source of infection to humans (Silva et al., 2011; Suman et al., 2012; Pallavi et al., 2015). Therefore, the present study was under taken with the objective to determine the prevalence and isolate Campylobacter spp. from variety of samples collected from Junagadh district, Gujarat State of India.

\section{Materials and Methods}

\section{Sample collection}

A total of 450 samples, comprised of 150 poultry meat, 150 intestinal (caeca) samples, 50 water, 50 equipment swab and 50 hand washing swab of workers from retail poultry meat shops from Junagadh district, Gujarat State were collected aseptically. In addition, 50 faecal samples were collected from children under 5 years of age with diarrhoea from human hospitals in Junagadh. All these samples were collected in sterilized polythene bags and transported to the laboratory in an icebox for microbiological analysis.

\section{Isolation of organisms}

These samples were enriched into blood free campylobacter selectivity broth and Preston broth with CCDA and campylobacter growth supplements under microaerophilic condition $\left(85 \% \mathrm{~N}_{2}, 5 \% \mathrm{O}_{2}\right.$ and $\left.10 \% \mathrm{CO}_{2}\right)$ at $42^{\circ} \mathrm{C}$ for 48 hours. Swabs were inoculated on blood free campylobacter selective agar with modified CCDA.

\section{Biochemical tests}

Oxidase, catalase, $\mathrm{H}_{2} \mathrm{~S}$ production on Triple sugar iron agar, indoxyl acetate hydrolysis and hippurate hydrolysis tests were performed to differentiate isolates at genus and species level as per methods described in the Burgey's Manual of Systemic Bacteriology.

\section{Polymerase Chain Reaction}

The presumptive Campylobacter isolates were further confirmed at genus and species level by polymerase chain reaction assay. DNA was extracted using a loopful of overnight grown culture of Campylobacter spp. suspended in $100 \mu \mathrm{l}$ of sterilized DNAse and RNAse-free milliQ water (Millipore, USA). After proper mixing, the tubes were kept in boiling water bath at $100^{\circ} \mathrm{C}$ for 10 min. Then, cell debris was removed by centrifugation and the tube was immediately transferred to ice and supernatant was used as DNA template for PCR assay. The oligonucleotide primers targeting lipid gene ' $l p x \mathrm{~A}$ ' were synthesized from Eurofins Genomics India Pvt. Ltd., India (Table 1). Species specific PCR performed to confirm Campylobacter spp. as described by Klenaet al.2004 with modifications. PCR was performed in a total reaction volume of $25 \mu \mathrm{l}$ containing 2X PCR Master Mix (Thermo Cat. No. K0171) with $2.5 \mu \mathrm{l}$ of $10 \mathrm{X}$ dream Taqbuffer, $2.5 \mu \mathrm{l}$ of $2 \mathrm{mM}$ of each dNTP, 15 pmol of each primer, $1 \mathrm{U}$ dream Taq polymerase with $2 \mu \mathrm{l}$ of bacterial DNA template extracted using DNeasy blood and tissue kit and nuclease-free water up to $25 \mu$. The mPCR amplification was performed in a thermal cycler with initial denaturation at 
$95^{\circ} \mathrm{C}$ for $5 \mathrm{~min}$, followed by 30 cycles of denaturation at $94^{\circ} \mathrm{C}$ for $30 \mathrm{~s}$, annealing at $50^{\circ} \mathrm{C}$ for $30 \mathrm{~s}$ and extension at $72^{\circ} \mathrm{C}$ for $1 \mathrm{~min}$. Final extension was carried out at $72^{\circ} \mathrm{C}$ for 10 min. The amplified products were electrophoresed in $2.0 \%$ agarose gel with ethidium bromide $(0.5 \mu \mathrm{g} / \mathrm{ml})$ and image was taken in a gel documentation system (Vilberlourmat)

\section{Results and Discussion}

On cultural isolation, Campylobacter spp. showed a characteristic small (1-2 mm), circular, flat to slightly raised, grey coloured colonies having a spreading or watery nature on Blood Free Campylobacter Selectivity Agar plates after incubation for $48 \mathrm{hrs}$. (Fig. 1). The colonies turned grayish and sticky when left for longer time on the agar plates. Gram negative, non-spore forming, mostly comma, short spirally curved, arc or "S" shaped rods were seen on Gram's staining (Fig. 2). Hanging drop preparation of $48 \mathrm{~h}$ incubated culture from agar plates showed typical cork screw darting type of motility.
None of the isolates grew under aerobic condition at $36^{\circ} \mathrm{C}$.

All these isolates were positive for oxidase, catalase and indoxyl acetate hydrolysis tests and negative for $\mathrm{H}_{2} \mathrm{~S}$ production on Triple sugar iron agar. The presumptive isolates showing positive hippurate hydrolysis test, positive indoxyl acetate hydrolysis test, resistance to cephalothin and sensitivity to nalidixic acid were considered as $C$. jejuni whereas isolates showing negative hippurate hydrolysis test, positive indoxyl acetate hydrolysis test, resistance to cephalothin and sensitivity to nalidixic acid were considered as $C$. coli.

Out of 500 samples processed for isolation, the highest no. of isolates was recovered in poultry intestinal contents $(38.67 \%)$, followed by poultry meat $(16.00 \%)$, equipment swab (10.00\%), worker hand washing swab (6.00\%), human stools $(4.00 \%)$. None of the isolate was present in water samples. A total of 92 campylobacters (18.40\%) were isolated comprising $64 \mathrm{C}$. coli (12.80\%) and 28 C.jejuni (5.60\%) (Table 2).

Table.1 Primers used to identify Campylobacter spp. isolates

Species $\quad$ Primer sequence (5'-3') Product size

C. jejuni F-ACAACTTGGTGACGATGTTGTA

$331 \mathrm{bp}$

R-CAATCATGDGCDATATGASAATAHGCCAT

C. coli

F- AGACAAATAAGAGAGAATCAG

$391 \mathrm{bp}$

R-CAATCATGDGCDATATGASAATAHGCCAT

$(\mathrm{F})=$ Forward primer; $(\mathrm{R})=$ Reverse primer 
Table.2 Campylobacters spp. isolated from poultry, human and environmental samples

\begin{tabular}{lllll}
\hline Type of samples & \multicolumn{2}{c}{ Samples Positive } & \multicolumn{2}{c}{ Positive } \\
& & Campylobacter spp.(\%) & C. coli (\%) & C. jejuni (\%) \\
\hline Poultry meats & 150 & $24(16.00)$ & $16(10.61)$ & $8(5.30)$ \\
Intestinal contents & 150 & $58(38.67)$ & $42(28.00)$ & $16(10.67)$ \\
Equipment swabs & 50 & $5(10.00)$ & $3(6.00)$ & $2(4.00)$ \\
Hand washing swabs & 50 & $3(6.00)$ & $2(4.00)$ & $1(2.00)$ \\
Human faeces & 50 & $2(4.00)$ & $1(2.00)$ & $1(2.00)$ \\
Water & 50 & - & - & - \\
\hline Total & $\mathbf{5 0 0}$ & $\mathbf{9 2}(\mathbf{1 8 . 4 0})$ & $\mathbf{6 4 ( 1 2 . 8 0 )}$ & $\mathbf{2 8}(\mathbf{5 . 6 0})$ \\
\hline
\end{tabular}

Fig.1 Campylobacter colonies on mCCD agar

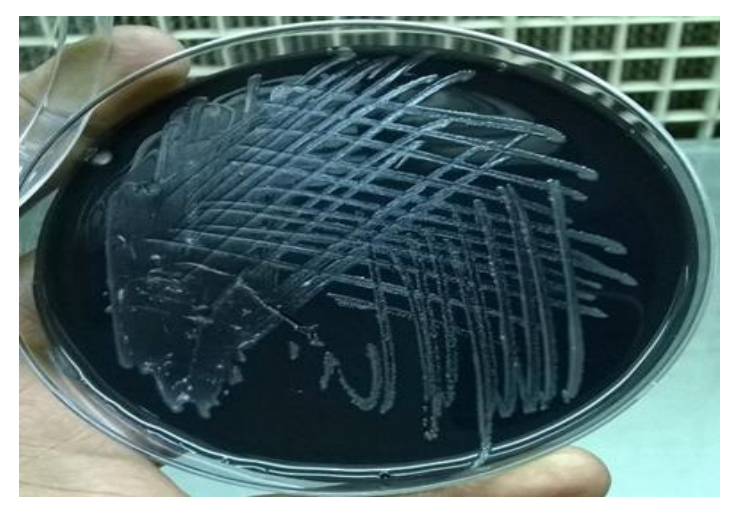

Fig.2 Gram's staining of Campylobacter organisms

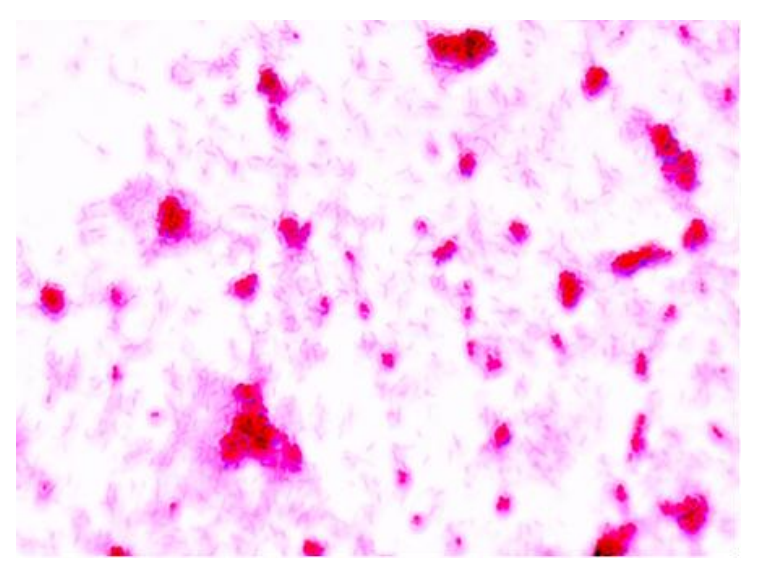


Fig.3 Confirmation of Campylobacter spp. by PCR targeting lpxA gene

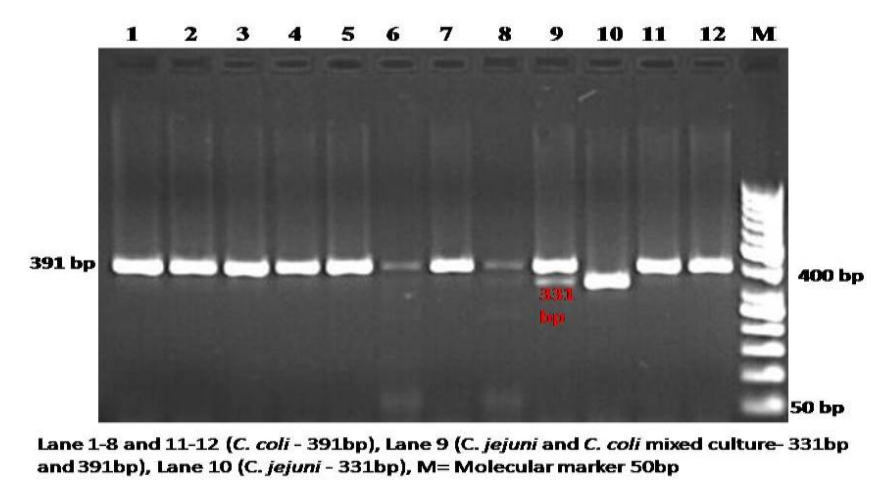

A multiplex PCR assay was employed for identification / confirmation of 2 species of Campylobacter namely, C. coli, and C. jejuni. The lipid gene, lpxA was targeted in this assay which yielded discriminatory band sizes for speciation. Out of the 92 isolates obtained in this study, 28 yielded preferred amplicon of 331 bp for $C$. jejuni and the rest 64 isolates gave amplicon of $391 \mathrm{bp}$ for $C$. coli (Fig. 3).

Blood-free campylobacter agar was used as the primary isolation medium during the present study. In the past, various researchers have used blood-free media for isolation studies of campylobacters with good efficiency (Merino et al., 1986; Oyarzabal et al., 2005). Typical colony morphology was found in all the culture positive plates. The cultures showed characteristic spiral or Sshaped cell morphology on crystal violet staining and were Gram negative on Gram staining studies.

A multiplex PCR assay targeting the lpxA gene as described by Klena et al., (2004) was performed to identify the species of Campylobacter. Only two of the four species targeted in the study were isolated in the present study and Kumar (2011) with slight modifications. The Campylobacter jejuni isolates amplified a 331 bp product, while Campylobacter coli isolates amplified a 391 bp product, thus differentiating into the respective species. Muller et al., (2006) and Eyles et al., (2006) have reported specificity in the identification of Campylobacter at species level using this assay. The mPCR based assay has been reported to be in agreement with the results of hippurate hydrolysis test for species level identification of campylobacters.

The overall prevalence $(18.40 \%)$ of Campylobacter spp. in present study correlates with the observation of Rajkumar et al., (2010) who was reported prevalence of $C$.jejuni and $C$. coli from poultry skin samples in small scale poultry dressing units of Northern India, as $18 \%$ from unorganized and $12 \%$ from organized farms. Similarly, Rizal et al., (2010) recorded $17.14 \%$ of the chicken samples and $8.57 \%$ of human samples were positive for $C$. jejuni.

Singh et al., (2009) and Sumankumar et al., (2012) also reported an overall prevalence of $12.7 \%$ and $10.67 \%$, respectively, from poultry meat and carcass collected from local poultry farms and retail markets of Bareilly which is lower as compared to present study. Suzuki and Yamamoto (2009) summarized the papers describing Campylobacter contamination of retail poultry meats and by-products in Japan and reported an average occurrence of 
approximately $60 \%$ which is higher compared to present study. Similarly, Tayde and Brahmbhatt (2012) also reported an overall prevalence of $34.66 \%$ from poultry meat and caecal contents collected from local retail markets of Anand, Gujarat which is higher compared to present study.

This variation in findings during the time of over 25 years may be due to variation in prevalence rate from time to time, disparity in hygienic and sanitary conditions of the poultry houses or use of different materials and methodology in different studies.

This study showed that out of a total of 92 Campylobacter isolates recovered, 64 $(69.56 \%)$ were confirmed as $C$. coli and 28 $(30.44 \%)$ as $C$. jejuni among poultry, human and environmental samples which was in concordance with the finding of Prasanna (2013) and Rajagunalan et al., (2014) at Pantnagar and Bareilly regions. Similar findings were also reported by other workers (Zorman et al., 2006 and Henry et al., 2011). In contrast to the findings of the present study, many of the workers reported a higher prevalence of $C$. jejuni in poultry than $C$. coli (Sumankumar et al., 2012; Tayde and Brahmbhatt, 2012). The reason for this difference in prevalence rates of $C$. jejuni and C. coli among poultry is unknown; however, impact of differences in the isolation procedures and geographic differences has been suggested by Zorman et al., 2006.

Although there is significant variation in prevalence of Campylobacter spp. in different species of animals as reported by different workers, the organism was found to be predominant in poultry meat. Campylobacter is normal inhabitant of intestinal tract of most of the animals. However faulty handling and processing with improper storage are responsible for presence of the organism in the meat. Besides, Campylobacter poses a potential risk for consumers especially in establishment lacking adequate sanitary measures to prevent cross contamination.

In conclusion the occurrence Campylobacter spp. in poultry intestinal contents, equipment swab and worker hands washing swab samples which indicate contamination of carcass may take place during slaughtering and/or post slaughtering processes. The isolation of Campylobacter spp. from clinical cases of children further prove the importance of infection that necessitates the need for proper preventive measures to control the infection in food production and consumption.

\section{Acknowledgments}

The authors are thankful to the Director of Research and Dean PG studies and Dean Veterinary college, Junagadh Agricultural University, Junagadh, for providing all required facility to conduct this research work.

\section{References}

Anonymous. 2005. An outbreak of Campylobacter jejuni enteritis in a school of Madrid, Spain. Eurosurveillance, 10: 118-121.

Behringer, M., Miller, W. G. and Oyarzabal, O. A., 2011. Typing of Campylobacter jejuni and Campylobacter coli isolated from live broilers and retail broiler meat by flaA RFLP, MLST, PFGE and REP-PCR. Journal of Microbiological Methods, 84:194-201.

CDC. 2008 Division of Food-Borne, Bacterial and Mycotic Diseases (DFBMD) Listing. Centers for Disease Control and Prevention, United States.

Datta, S., Niwa, H. and Itoh, K., 2003. Prevalence of 11 pathogenic genes of Campylobacter jejuni by PCR in strains isolated from humans, poultry meat and 
broiler and bovine faeces. Journal of Microbiological Methods, 52: 345-348.

Eyles, R. F., Brooks, H. J. L., Townsend, C. R., Burtenshaw, G. A., Heng, N. C. K., Jack, R. W. and Weinstein, P., 2006. Comparison of Campylobacter jejuniPFGE and Penner subtypes in human infections and in water samples from the Taieri River catchment of New Zealand. Journal of Applied Microbiology, 101: 18-25.

Ghorbanalizadgan, M., Bakhshi, B., Lili, A.K., Najar-Peerayeh, S. and Nikmanesh, B.,2014. A molecular survey of Campylobacter jejuni and Campylobacter coli virulence and diversity. Iranian Biomedical Journal, 18: 158.

Ghosh, R., Uppal, B., Aggarwal, P., Chakravarti, A. and Jha, A.K., 2013. Increasing antimicrobial resistance of Campylobacter jejuni isolated from paediatric diarrhea cases in a tertiary care hospital of New Delhi, India. Journal of Clinical and Diagnostic Research, 7: 247.

Henry, I., Reichardt J., Denis M., Cardinale E., 2011. Prevalence and risk factors for Campylobacter spp. in chicken broiler flocks in Reunion Island (Indian Ocean). Preventive Veterinary Medicine, 100: 6470.

Klena, J. D., Parker, C. T., Knibb, K., Ibbitt, J. C., Devane, P. M. L., Horn, S. T., Miller, W. G. and Konkel, M. E., 2004. Differentiation of Campylobacter coli, Campylobacter jejuni, Campylobacter lariand Campylobacter upsaliensis by a multiplex PCR developed from the nucleotide sequence of the lipid A gene lpxA. Journal of Clinical Microbiology, 42:5549-5557.

Kumar, A., Agarwal, R.K., Bhilegaonkar, K.N., Shome, B.R. and Bachhil, V.N., 2001. Occurrence of Campylobacter jejuni in vegetables. International Journal of Food Microbiology, 67:153-155.

Kumar, S. M., 2011. Studies on molecular heterogeneity of thermophilic Campylobacter isolates from man and animals. Thesis, M.V.Sc. Deemed
University, Indian Veterinary Research Institute, Izatnagar, India. pp. 99.

Merino, J. F., Agulla, A. and Villasante, P. A., 1986. Comparative Efficacy of Seven Selective Media for Isolating Campylobacter jejuni. Journal of Clinical Microbiology, 24:451-452.

Müller, J., Schulze, F., Müller, W and Hänel, I., 2006. PCR detection of virulenceassociated genes in Campylobacter jejuni strains with differential ability to invade Caco- 2 cells and to colonize the chick gut. Veterinary Microbiology, 113:123-129.

Oyarzabal, O. A., Macklin, K. S., Barbaree, J. M. and Miller, R. S., 2005. Evaluation of agar plates for direct enumeration of Campylobacter spp. from poultry carcass rinses. Applied and Environmental Microbiology, 71:3351-3354.

Pallavi., Kumar, A., Kumar. M.S. and Bagalakote. P.S., 2015. Comparative analysis of cultural isolation and PCR based assay for detection of Campylobacter jejuni and Campylobacter coli in foods of animal origin. Journal of Animal Research, 5: 21-25.

Prasanna, K.V., 2013. Isolation and molecular characterization of Campylobacter jejuni and Campylobacter coli from human and poultry caeca as well as meat. MVSc Thesis Submitted to G.B.P.U.A \&T., Pantnagar, India.

Rajagunalan, S., Bisht, G., Pant, S., Singh, S. P., Singh, R.and Dhama, K., 2014. Prevalence and molecular heterogeneity analysis of Campylobacter jejuni and Campylobacter coli isolated from human, poultry and cattle, in Pantnagar, India. Veterinarskiarhiv, 84: 493-504.

Rajendran, S., Babji, P., George, A.T., Rajan, D.P., Kang, G. and Ajjampur, S.S., 2012. Detection and species identification of Campylobacter in stool samples of children and animals from Vellore, south India. Indian Journal of Medical Microbiology, 30: 85-88.

Rajkumar, R. S., Yadav, A. S., Rathore, R. S., Mohan, H. V. and Singh, R. P., 2010. Prevalence of Campylobacter jejuni and 
Campylobacter coli from unorganized and organized small scale poultry dressing units of Northern India. Journal of Veterinary Public Health, 8: 1-5.

Rizal, A., Kumar, A. and Vidyarthi, A.S., 2010. Prevalence of Pathogenic Genes in Campylobacter jejuni Isolated from Poultry and Human. International Journal of Food Safety, 12:29-34.

Ruiz-Palacios, G. M., 2007. The health burden of Campylobacter infection and the impact of antimicrobial resistance: playing chicken. Clinical infectious Diseases, 44(5):701-703.

Scallan, E., Hoekstra, R. M., Angulo, F. J., Tauxe, R. V., Widdowson, M. A., Roy, S. L., Jones, J. L. and Griffin, P. M., 2011. Foodborne illness acquired in the United States-major pathogens. Emerg Infect Dis., 35: 85-93.

Silva, J., Leite, D., Fernandes, M., Mena, C., Gibbs, P. A. and Teixeira, P., 2011. Campylobacter spp. as a foodborne pathogen: a review. Frontiers in Microbiology, 2: 200.

Singh, R., Singh, P. P., Rathore, R. S., Dhama, K. and Malik, S. V. S., 2009. Prevalence of Campylobacter jejuni and Campylobacter coli in chicken meat and carcasses collected from local poultry farms and retail shops of Bareilly, Uttar Pradesh, India. Indian Journal of Comparative Microbiology, Immunology and Infectious Disease, 30: 90-93.
Suman Kumar, M., Ashok Kumar, Rizal, A., Bhilegaonkar, K.N., Rathore, R.S., Lokesh, K.M. and Agarwal, R.K., 2012.Molecular Characterization of Campylobacter jejuni isolates of poultry origin. Journal of Veterinary Public Health, 10(2): 65-71.

Suzuki, H. and Yamamoto, Z., 2009. Review: Campylobacter contamination in retail poultry meats and by-products in Japan: A literature survey. Food Control, 20: 531537.

Tam, C. C., Rodrigues, L. C., Viviani, L., Dodds, J. P., Evans, M. R., Hunter, P. R., Gray, J. J., Letley, L. H., Rait, G., Tompkins, D. S. and O'Brien, S. J., 2011. Longitudinal study of infectious intestinal disease in the UK (IID2 study): incidence in the community and presenting to general practice. Gut, 61(1):69-77.

Tayde, R.S. and Brahmbhatt, M. N., 2012. Virulence Profile of Campylobacter spp. isolated from Poultry in Anand City, Gujarat. Journal of Veterinary Public Health, 10(1): 1-5.

Zorman, T., Heyndrickx, M., UzunovicKamberovic, S. and Mozina, S. S., 2006. Genotyping of Campylobacter coli and $C$. jejuni from retail chicken meat and human with campylobacteriosis in Slovenia and Bosnia and Herzegovina. International Journal of Food Microbiology, 110: 2433.

\section{How to cite this article:}

Sindhi, S. H., B. S. Mathapati, V. L. Parmar, S. Marandi, M. Sumankumar, B. B. Javia, S. N.Ghodasara, J. B. Kathiriya, K. R. Bhedi and Patel, J. S. 2020. Techniques for Prevalence of Campylobacter spp. Isolated from Poultry, Human and Environment in Junagadh District of Gujarat, India. Int.J.Curr.Microbiol.App.Sci. 9(09): 3319-3326. doi: https://doi.org/10.20546/ijcmas.2020.909.413 